\title{
LOS LIIMITES DEL REFERENDO SOBRE EL TLC COMO INSTRUMENTO DE PARTICIPACIÓN POLÍTICA EN COSTA RICA
}

\section{THE LIMITS OF CAFTA REFERENDUM AS A TOOL FOR POLITICAL PARTICIPATION IN COSTA RICA}

\section{Alberto Cortés Ramos*}

\section{ÍNDICE}

\author{
PRESENTACIÓN \\ PREMISA CONCEPTUAL: COMUNICACIÓN POLÍTICA Y UNA POLÍTICA QUE ES CADA VEZ MÁS MEDIÁTICA ........... 33 \\ LA ESTRUCTURA MEDIÁTICA COSTARRICENSE Y EL PAPEL DE LOS MEDIOS EN EL REFERENDO . . . . . . . . 35 \\ Televisión \\ La prensa escrita \\ Radio e Internet \\ LAS REGLAS DEL JUEGO DEL REFERENDO Y LA DEMOCRACIA COMUNICACIONAL \\ Financiamiento de las partes en el referendo \\ La agenda mediática de los principales medios de comunicación $\ldots \ldots \ldots \ldots \ldots \ldots \ldots \ldots \ldots \ldots$ \\ La participación del Ejecutivo \\ La campaña del Miedo del Sí y el Memorando Casas-Sánchez \\ La campaña del No: la gente hace una campaña de campañas \\ Internet como nueva arena de disputa comunicacional \\ CONCLUSIONES \\ BIBLIOGRAFÍA \\ PUBLICACIONES PERIÓDICAS \\ BASES DE DATOS
}

RESUMEN

El presente artículo analiza el referendo sobre el Tratado de Libre Comercio con Estados Unidos, Centroamérica y República Dominicana que se realizó en Costa Rica durante el año 2007. La premisa de la que parte el autor es que, por su gran significado político y por la complejidad de su dinámica socio-política, el referendo debe ser analizado desde diversas perspectivas, incluyendo la comunicación política. Desde esa perspectiva, el autor destaca en su análisis varios elementos: primero, la estructura del campo mediático en la que se desarrollaron las campañas, incluyendo televisión, 
radio, prensa escrita e Internet. Segundo, las reglas del juego con las que se desarrolló el referendo, incluyendo el tema del financiamiento, la agenda de los principales medios comerciales, el papel del Ejecutivo y, finalmente, la estrategia y el contenido de las campañas desarrolladas por los grupos a favor (Sí) y en contra (No) del TLC. Una mención especial merece la Internet como una nueva arena de disputa comunicacional en Costa Rica. A lo largo del artículo se evidencia las condiciones de desigualdad en las reglas de juego, recursos económicos y agendas mediáticas, incluyendo el uso del miedo como recurso mediático, que claramente favorecieron a los grupos que apoyaban el TLC, pero que limitaron sustantivamente el contenido democrático del referendo. El artículo concluye señalando aspectos que deben modificarse para democratizar el referendo en Costa Rica.

PALABRAS CLAVE: COSTA RICA * REFERÉNDUM * COMUNICACIÓN POLÍTICA * MEDIOS DE COMUNICACIÓN $*$ CAMPAÑAS MEDIÁTICAS $*$ USO DEL MIEDO $*$ PARTICIPACIÓN DEMOCRÁTICA * CAFTA

\section{ABSTRACT}

This article analyses the referendum on the Free Trade Agreement with the United States, Central America and the Dominican Republic (CAFTA), which took place in Costa Rica during 2007. The premise of the author is that, due to its great political significance and its socio-political complexity, the referendum must be analyzed from various approaches, including political communication. From that perspective, the author points out several elements: first, the media structures in which the communication campaigns, in favor and against, were developed. This includes television, radio, newspapers and Internet. Second, the referendum's rules of the game, including the issues of funding, the media agenda setting, the role of the Executive and, finally, the strategy and content of the campaigns developed by the groups in favor (Yes) and against (No) CAFTA. Internet deserves special mention as a new arena of contention communications in Costa Rica. Throughout the article, the author showed evidence of the inequality in the rules of the game, economic resources and media agendas, including the use of fear as political resource, which clearly favored groups that supported CAFTA, but that substantially limited the democratic content of the referendum. The article concludes pointing out lessons and aspects that should be modified in order to democratize referendum in Costa Rica.

KEYWORDS: COSTA RICA * REFERENDUM * POLITICAL COMMUNICATION * MEDIA * MEDIA CAMPAIGNS $*$ USE OF FEAR $*$ DEMOCRATIC PARTICIPATION $*$ CAFTA

\section{PRESENTACIÓN}

Este artículo analiza el proceso de referendo sobre el Tratado de Libre Comercio entre Estados Unidos, República Dominicana y Centroamérica que se realizó en Costa Rica el 7 de octubre de 2007, desde la perspectiva de la comunicación política. Desde este abordaje, se discute las limitaciones que tiene el referendo como instrumento de participación democrática. En esa línea, interesa hacer un balance para obtener lecciones que, por un lado, evidencien las formas y modos de uso antidemocrático de instrumentos de consulta ciudadana o popular $y$ que, por el contrario, permitan hacer propuestas orientadas a profundizar el carácter democrático de estos instrumentos.

En lo que respecta al caso de estudio, el referendo en Costa Rica tiene particular relevancia por varias razones: fue la primera ocasión en que se puso en práctica este tipo de consulta en la historia del país. Segundo, fue la primera vez que se consultó de esta forma un tratado de libre comercio entre un país 
latinoamericano y los Estados Unidos. Tercero, en términos de la trayectoria del estilo de desarrollo de Costa Rica, la consulta condensaba una intensa y larga disputa por la orientación del estilo de desarrollo nacional y la forma de Estado. Este pulso se había prolongado durante al menos los últimos tres lustros, enfrentando a los grupos de poder con organizaciones sociales, grupos ciudadanos y movimientos sociales (Cortés, 2007; Rovira, 2006). En ese sentido, este proceso constituye un complejo laboratorio socio-político y comunicacional que amerita ser estudiado con detenimiento $y$ desde muchas aristas, incluyendo la comunicación política.

\section{PREMISA CONCEPTUAL: COMUNICACIÓN POLIITICA Y UNA POLÍTICA QUE ES CADA VEZ MÁS MEDIÁTICA}

Este artículo se inscribe dentro de la comunicación política conceptualizada como espacio de interacción interdisciplinaria entre las ciencias de la comunicación y la ciencia política, aunque no exclusivamente pues también recibe aportes de otras disciplinas, tales como la psicología y la sociología. En términos generales, la comunicación política estudia la dimensión comunicacional de los procesos políticos (Monzón, 2000).

Con el surgimiento y consolidación de la esfera de la opinión pública, la ampliación de los espacios democráticos y la expansión de los medios de comunicación colectiva, la comunicación política analiza la interacción entre gobernantes y gobernados, élites de poder y ciudadanía, gobiernos y oposición, mayorías y minorías, relaciones mediadas por la prensa $y$ los medios de comunicación, también objeto de estudios de esta disciplina. Estas interacciones se realizan por medio de una serie de prácticas que incluyen los discursos políticos de los distintos actores colectivos, la comunicación informativa, los análisis de opinión pública, las relaciones públicas, la publicidad y el marketing político (Pérez, 2003).

El presente artículo es un estudio de comunicación política contemporánea y parte de la premisa de que la mediación entre política y comunicación es cada vez más intensa debido al acelerado proceso de desarrollo de los medios de comunicación que hemos atestiguado en las últimas décadas, sobre todo a partir de la irrupción de la televisión como principal medio de comunicación, cuyo imperio aún prevalece a pesar del desarrollo de las nuevas tecnologías de la información y la comunicación (TICs) que, sin lugar a dudas, modificarán la forma en que interactuamos y nos comunicamos políticamente (del Rey Morató, 2007).

Una de las características principales de la comunicación política es la creciente importancia que adquieren las imágenes y el lenguaje audiovisual en detrimento del contenido del mensaje, siendo cada vez más evidente la existencia de una realidad virtual que tiene un efecto sobre la práctica $y$ la cultura política en nuestras sociedades. No es casual que diversos autores utilizan la expresión "democracia mediática" para dar a entender el peso central que ejercen los medios en la arena $y$ los procesos políticos contemporáneos (Rospir, 2003: 46-48). En buena medida, la profundización de la política de la imagen o, mejor aún, de la política como imagen, ha sido resultado de la expansión del imperio de la televisión en la cultura contemporánea.

Si bien es cierto, con la expansión del Internet posiblemente estemos entrando a una nueva revolución tecnológica que transformará la forma en que se hace comunicación política $y$, posiblemente, generará nuevas prácticas y nuevas formas de liderazgo (Del Rey Morató, 2006: 19), también es cierto que aún es un momento de transición en que el viejo $y$ decadente imperio mediático de la televisión sigue siendo hegemónico.

Esta sigue siendo la realidad prevaleciente en el caso costarricense. De hecho, el predominio de la televisión se confirmó en un sondeo telefónico realizado por la Escuela de Ciencias Políticas de la Universidad de Costa Rica en septiembre de 2007 (Cortés y Fournier, 2007) en que se le preguntó a las personas entrevistadas cómo se informaba sobre el TLC en el marco del proceso de referendo y el 40,5\% indicó que por medio de la TV, cifra que duplicaba al siguiente medio de información, la prensa escrita, como se observa en la figura 1 : 
FIGURA 1

¿CÓMO SE INFORMA SOBRE EL TLC?

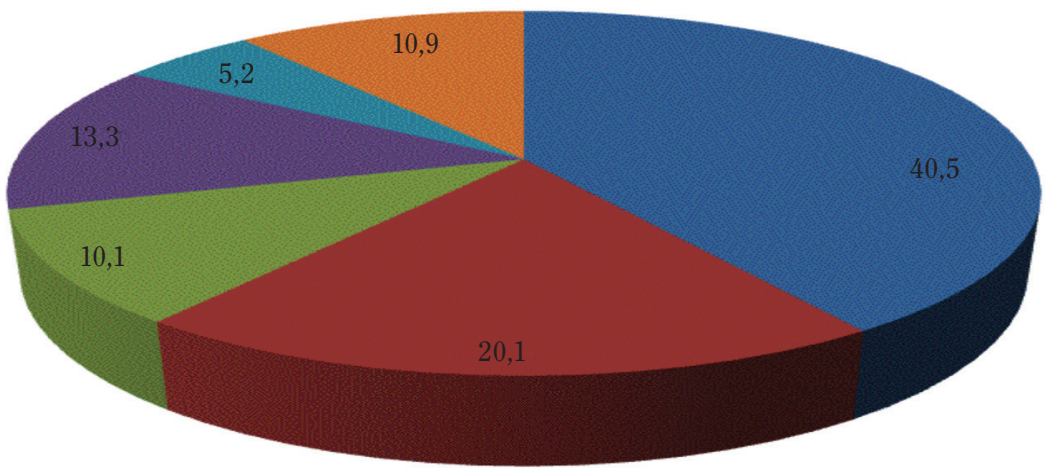

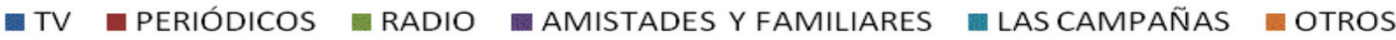

Fuente: Cortés Ramos, Alberto y Marco Fournier Facio. Encuesta sobre el TLC y el referendo. Escuela de Ciencias Políticas, Universidad de Costa Rica, setiembre, 2007.

Si bien se requiere mayor investigación en este campo, los resultados señalados en la Figura 1 dan algunas pistas sobre la forma en que se estructuró el campo mediático en que se desenvolvió el referendo, evidenciando que para profundizar el contenido democrático del sistema político costarricense hay que hacer una reflexión seria sobre la estructura, dinámica y orientación de los medios de comunicación, las reglas de juego del proceso de referendo en lo que concierne a la comunicación política, el papel del auditorio (receptor), el papel de los distintos actores políticos participantes del proceso político, el papel de los actores mediáticos (medios de comunicación) y el papel del árbitro, en este caso el Tribunal Supremo de Elecciones (TSE).

En una encuesta posterior al referendo realizada por los mismos investigadores, se preguntó nuevamente sobre la forma en que se informaron sobre el TLC a las personas entrevistadas. El resultado se puede observar en la figura 2:

\section{FIGURA 2}

\section{DIVERSAS FUENTES DE INFORMACIÓN CONSULTADAS} POR LA CIUDADANÍA DURANTE EL REFERENDO

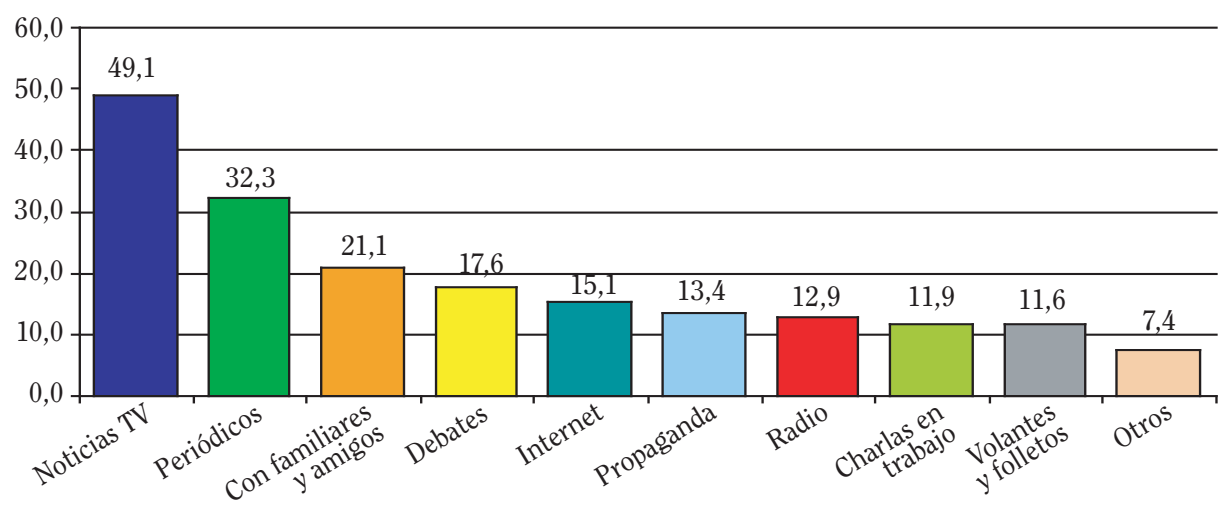

Fuente: Cortés Ramos, Alberto y Marco Fournier Facio. Encuesta Post-referendo. Escuela de Ciencias Políticas, Universidad de Costa Rica, abril, 2008. 
Los resultados de esta encuesta telefónica realizada en julio de 2008 (ocho meses después del referendo) confirma algunos elementos con respecto a la encuesta mencionada anteriormente: el claro predominio de los noticiarios de TV (canales nacionales) como medio de información y la gran cantidad de otras fuentes que utilizó la ciudadanía para formar su opinión y tomar su decisión. En este caso, llama la atención que Internet aparece por encima de la radio como fuente consultada.

\section{LA ESTRUCTURA MEDIÁTICA COSTARRICENSE Y EL PAPEL DE LOS MEDIOS EN EL REFERENDO}

El primer aspecto por destacar de lo que se denomina la cancha mediática es que en la estructura de propiedad de los medios hay una alta concentración de la propiedad, lo que tiende a reflejarse en la orientación ideológica y una agenda mediática claramente sesgada a favor de posiciones neoliberales en términos discursivos de estos medios.

\section{TELEVISIÓN}

Esta característica es particularmente dominante en el caso de la televisión comercial en los que predominan dos canales al nivel nacional: el seis $y$ el siete. En la figura 3 se puede observar el desenvolvimiento de las preferencias de la opinión pública en términos de la televisión en las últimas dos décadas:

FIGURA 3

EVOLUCIÓN HISTÓRICA DE PREFERENCIAS DE CANALES DE TV, 1988-2006

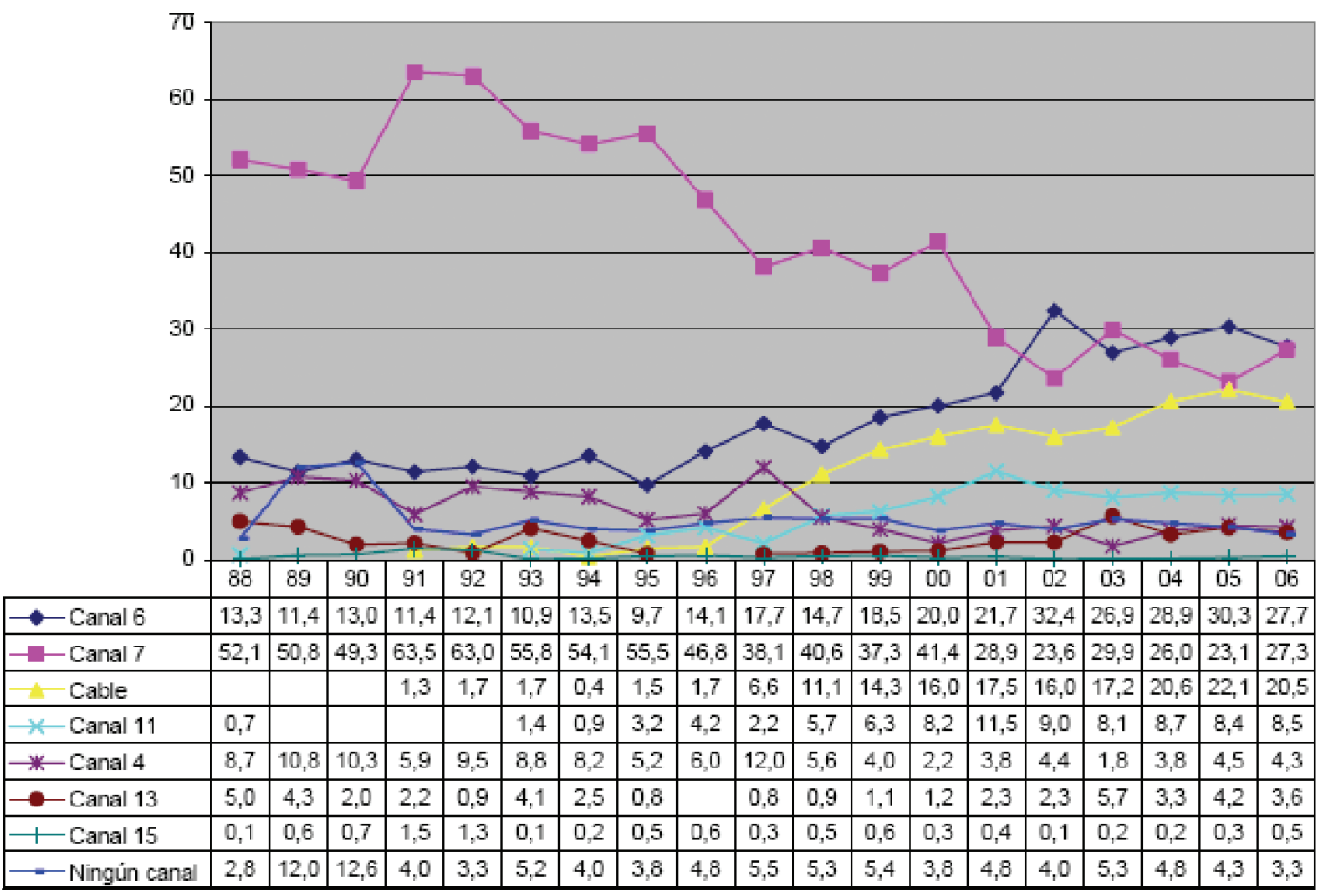

Fuente: Poltronieri, Jorge. Encuesta estructura de opinión pública. Escuela de Matemáticas, Universidad de Costa Rica, 2006. 
En esta figura se hace evidente el nivel de concentración de las preferencias en estos dos canales nacionales. En el caso del canal 7, el más antiguo, tuvo un período de claro predominio hasta mediados de la década pasada con preferencias superiores al 50 por ciento para luego empezar a decaer hasta estabilizarse a inicios de la década actual, con una preferencia cercana al 30 por ciento.

En este mismo período es destacable el ascenso de las preferencias por canal 6 y también de la televisión por cable a partir de mediados de los noventa, una evidencia más del creciente proceso de transnacionalización que vive el país desde esa época.

Obviamente, este oligopolio mediático tiene implicaciones sobre el contenido de la información que recibe la ciudadanía, pues ambos canales tienen noticiarios que son un referente importante en el consumo de información nacional, situación que no es revertida por la televisión por cable que tiene, en su mayoría, canales y noticieros extranjeros que alimentan el enfoque internacional de los programas de noticias nacionales (caso CNN).

En lo que respecta a los noticieros nacionales, en términos generales tienen una orientación discursiva bastante similar, en tanto que favorecen posiciones pro-libre competencia y pro-apertura comercial aunque con matices en el estilo de presentación, siendo mucho más tendencioso y amarillista Repretel (canal 6). En el caso del canal estatal, el 13, tiene una orientación claramente marcada por el gobierno de turno. El único canal nacional con una orientación disonante y crítica es el canal quince de la Universidad de Costa Rica (UCR) que tiene una cobertura muy baja.

\section{LA PRENSA ESCRITA}

En la prensa escrita, la estructura se modifica levemente, aunque mantiene importantes elementos en común con la televisión, como se observa en la siguiente figura 4 :

\section{FIGURA 4}

\section{EVOLUCIÓN DE PREFERENCIAS EN LA PRENSA ESCRITA, 1988-2006}

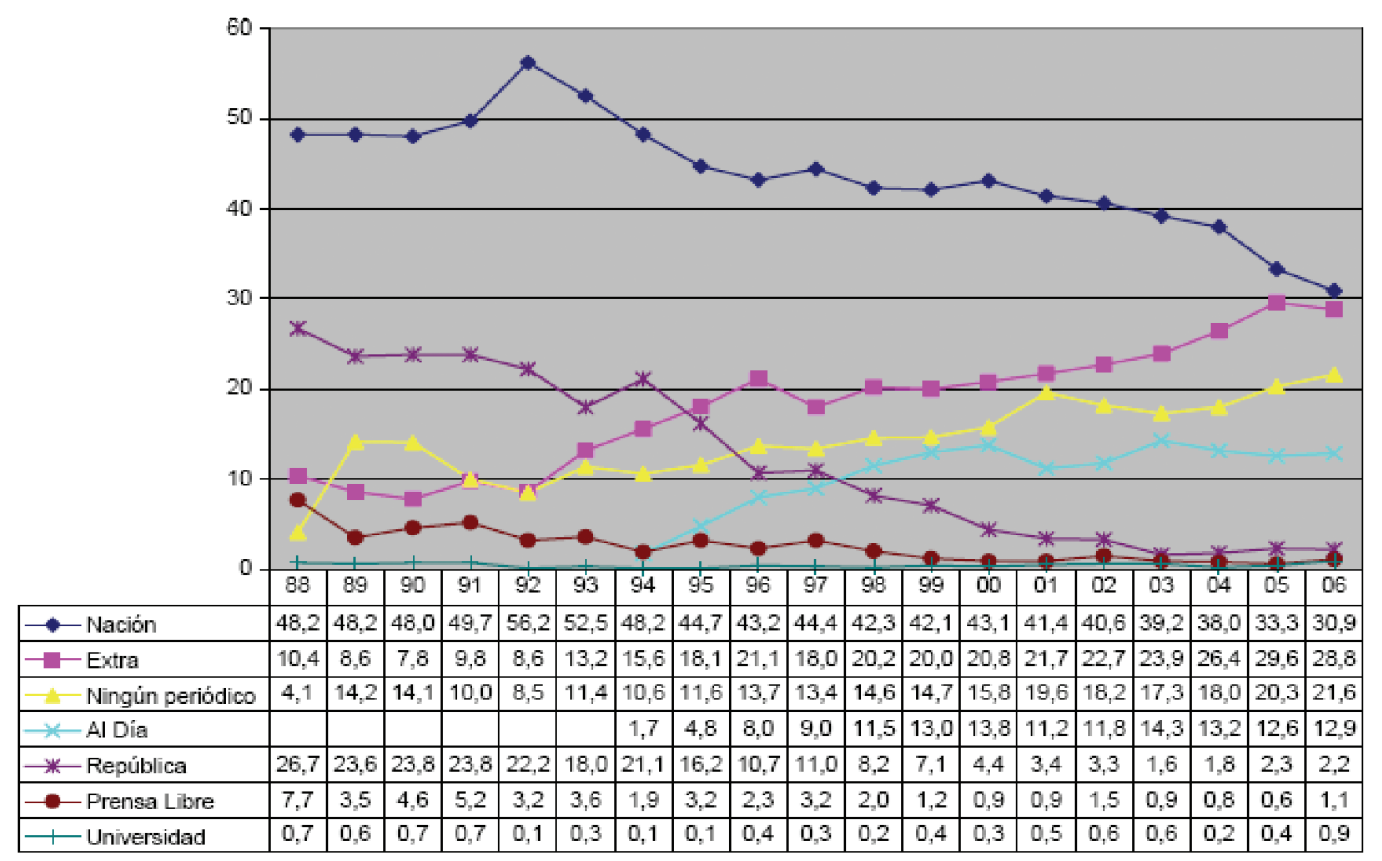

Fuente: Poltronieri. Encuesta estructura de opinión pública. Escuela de Matemáticas, Universidad de Costa Rica, 2006. 
En este caso, hay varias tendencias significativas a destacar: primero, el declive del periódico La Nación que durante varias décadas tuvo una clara hegemonía en la definición de la agenda mediática del país. Este medio alcanzó su clímax en términos de preferencias en 1992 (56,2\%), punto a partir del cual empezó a descender, llegando a su punto más bajo en el 2006 (30,9\%). Hay dos tendencias más a mencionar que, posiblemente, contribuyan a explicar la primera: por un lado, el crecimiento del Diario Extra ("La Extra"), periódico de corte amarillista que pasó de tener un $8,6 \%$ de preferencias en 1992 a un $28,8 \%$ de preferencias en 2006. Es decir, un incremento de $20 \%$ en el mismo lapso en que La Nación perdió 25\%. El ascenso de La Extra es importante en este contexto, sobre todo por el papel que jugó durante el referendo abriendo espacio a las posiciones del "NO", posiciones que fueron prácticamente bloqueadas cuando no manipuladas por los otros medios masivos. Esta tendencia no debe ser interpretada como un alineamiento de este periódico con el "NO", sino más bien como parte de una inteligente estrategia comercial que buscaba aprovechar una demanda "insatisfecha" de lectores opuestos al TLC o con dudas, que no podían llenar sus necesidades de información en los medios escritos del grupo Nación. Sin embargo, lo que este periódico hizo no fue otra cosa que abrir espacios equivalentes a actores del sí y del NO.

La otra tendencia relevante, es el creciente porcentaje que, año con año, responde que no lee medios escritos, tendencia que pasó del $8,5 \%$ en 1992 a 21,6\% en 2006. Posiblemente, este sea otro factor que contribuye a explicar el descenso de las preferencias de La Nación y de otros medios.

Hay dos puntos más que interesa subrayar: primero, el grupo empresarial "Nación" ha intentado generar otros medios, posiblemente con el propósito de capitalizar a su favor el cambio en la estructura de preferencias de consumo informativo (por ejemplo, el descenso de preferencias en el caso de La República y La Prensa Libre) y, por otro lado, para intentar frenar el acelerado crecimiento del diario $L a$ Extra. En esa línea, a mediados de los noventa el grupo Nación creó el periódico Al Día y, de manera reciente, el periódico La Teja, de orientación sensacionalista claramente orientado a competir con La Extra, propósito que no pareciera haber logrado hasta el momento.

Un medio que no podría dejar de mencionarse es el Semanario Universidad de la UCR que, a pesar de tener una circulación reducida, tiene un impacto importante en los círculos de toma de decisiones $y$ de sectores que forman opinión. No en vano, fue este medio el que denunció el Memorando Casas-Sánchez que terminó costándole el puesto al segundo Vicepresidente Kevin Casas del Gobierno, como se explicará con detalle más adelante.

En términos ideológicos, La Nación, Al Día, La Teja y La República tienen una orientación neoliberal y pro-empresarial, claramente reflejada en posiciones pro-mercado y proapertura. En el caso de La Nación, habría que agregar que juega un papel clave en la estructuración del discurso, la visión estratégica y la agenda de los grupos de poder y sus representantes políticos, por lo que puede ser considerada como una suerte de "intelectual orgánico" del gran capital nacional y transnacional en el país. Esto no es casual, el grupo Nación es, aparte de actor mediático, un importante actor económico con intereses y ramificaciones en otras áreas de la economía nacional, incluyendo la producción de azúcar y etanol, además de tener intereses directos en la apertura de las telecomunicaciones (Semanario Universidad, 2007).

\section{RADIO E INTERNET}

Los otros dos principales medios de comunicación son la radio e Internet. En el caso de la radio, tanto por la gran cantidad de estaciones que existe, por cobertura y por costo es, sin lugar a dudas, el medio más democrático y ha jugado un papel clave en la divulgación de posiciones que se contraponen a los temas de la agenda mediática de los grandes medios comerciales televisivos y escritos. En la siguiente figura 5 se observa la evolución de las preferencias de los radioescuchas, llamando la atención el creciente proceso de atomización de la audiencia y el 
aumento significativo de las personas que responden no tener una estación favorita (más del $20 \%$ en 2006). Es importante destacar que existen una gran cantidad de radios regionales que juegan un papel fundamental en la divulgación de los debates políticos. También destaca el papel de Radio Universidad y Radio $U$ juvenil, que aparte de tener una orientación crítica y abierta, la última tiene un gran peso en la audiencia juvenil.

FIGURA 5

EVOLUCIÓN DE PREFERENCIAS EN LA RADIO, 1988-2006

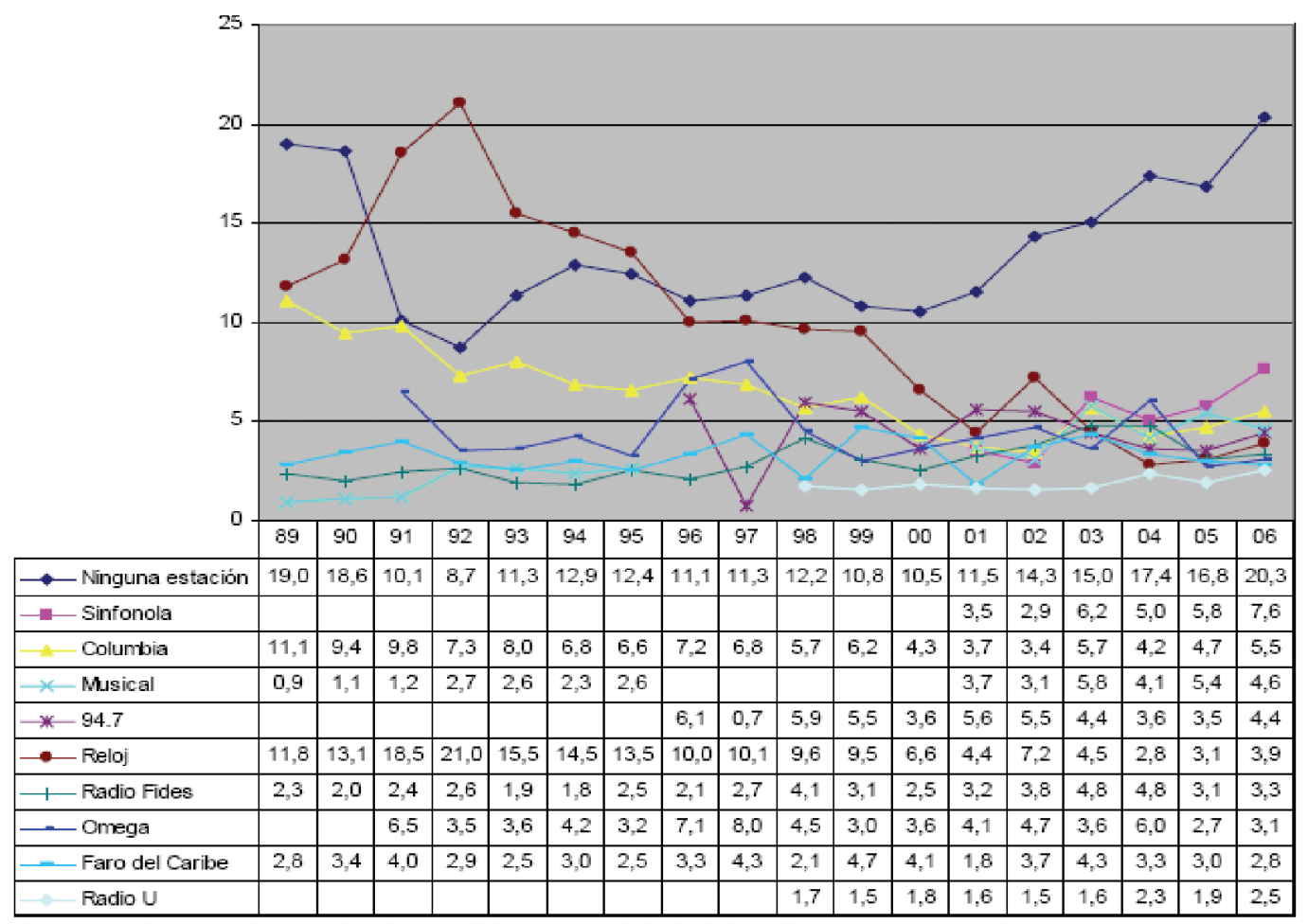

Fuente: Poltronieri. Encuesta estructura de opinión pública. Escuela de Matemáticas, Universidad de Costa Rica, 2006.

Aunque su desarrollo es incipiente y su acceso aún limitado a sectores medios y urbanos, el caso de Internet requiere particular atención debido a que hay indicios de que se constituirá en una de las principales arenas comunicacionales de la política costarricense en el futuro cercano a juzgar por la activa participación que en este espacio tuvieron las nuevas generaciones (menores de treinta años) en el debate sobre el referendo. En este caso, las personas jóvenes utilizaron masivamente este instrumento y muchas de las mejores acciones mediáticas del Movimiento Patriótico del NO provinieron de iniciativas individuales, incluyendo videos, que circularon en Internet por medio de Youtube, listas electrónicas, blogs y páginas Web.

Si bien en los estudios realizados por la Escuela de Ciencias Políticas (Figuras 1 y 2), se nota el limitado acceso a Internet como fuente de información para el referendo (menos del $5 \%$ en la primera y poco más del $15 \%$ en la segunda), es muy probable que esos porcentajes no estén tomando en cuenta el impacto que tuvo Internet en términos de distribución y canalización de información redistribuida 
en las comunidades por medio de los Comités Patrióticos ${ }^{1} y$ organizaciones sociales. En todo caso, este es un tema que amerita más estudio.

En síntesis, en términos estructurales, es evidente que el campo mediático estaba claramente desbalanceado para el amplio y diverso sector de la sociedad costarricense que se oponía al TLC. A continuación se analizará cómo afectaron las reglas del juego del referendo a este campo mediático.

\section{LAS REGLAS DEL JUEGO DEL REFERENDO Y LA DEMOCRACIA COMUNICACIONAL}

En esta sección se discuten algunos elementos básicos que tendría que haber contemplado el referendo para que se desarrollara como un proceso verdaderamente democrático. Hay varios de estos elementos que tienen que ver con la comunicación política.

\section{FINANCIAMIENTO DE LAS PARTES EN EL REFERENDO}

El primero de ellos era el tema del acceso a financiamiento público para que las dos partes, el sí y el NO, pudieran pautar sus posiciones en los principales medios de comunicación masiva. No debemos obviar que, aunque todavía de forma desigual, en la legislación electoral costarricense existe financiamiento público para los partidos políticos que obtienen cierto número de votos en las campañas electorales. Sin embargo, la interpretación restrictiva que hizo el TSE de este aspecto central para el proceso, hizo que el campo mediático en que se desenvolvió el referendo, ya de previo desigual en detrimento del NO, terminara siendo claramente desigual.

Esta situación fue así básicamente porque el sector que apoyaba al TLC contaba con el apoyo financiero y masivo del gran capital nacional y transnacional, que no escatimó

1 Comités Patrióticos No al TLC fue el nombre que adquirió la organización de los sectores contrarios al TLC en la dimensión territorial. Las unidades de referencia eran los cantones y distritos. Al final del proceso se calcula que había cerca de 200 Comités Patrióticos en todo el país. esfuerzos para pautar en publicidad y propaganda lo que fuera necesario para ganar. Ello se reflejó en el monto invertido en cada campaña durante los cuatro meses que duró el referendo. De hecho, según datos publicados en el Semanario Universidad del 11 de octubre de 2007, la pauta total en televisión fue de 1444 anuncios, de los que 1319 (91,3\%) fueron del sí frente a 125 $(8,7 \%)$ que logró pautar el No (ver figura 6).

FIGURA 6

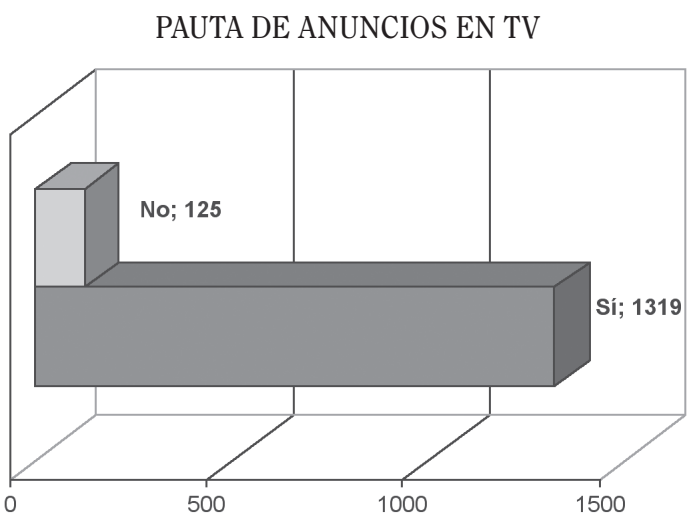

Fuente: Semanario Universidad, 18/11/07.

En términos del gasto en publicidad, también la diferencia fue abrumadora: en el caso del sí pautaron 888 millones de colones frente a los del No que pautaron poco más de 116 millones de colones (figura 7).

\section{FIGURA 7}

\section{GASTO PUBLICITARIO EN TV (MILLONES DE COLONES)}

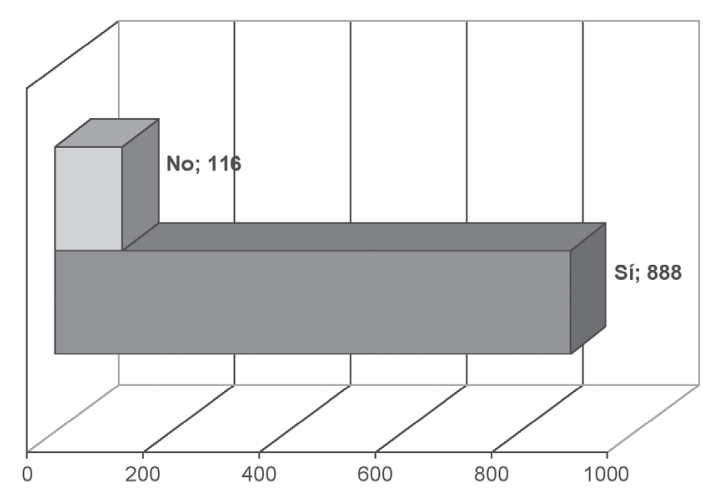

Fuente: Semanario Universidad, 18/11/07. 
Estos datos dan una idea del gran desbalance mediático que hubo durante el proceso de referendo en términos de la publicidad política. Sin embargo, como bien indican los estudiosos de la comunicación política (del Rey Morató, 2006), el campo mediático en el que se desarrolla la comunicación política es más amplio que el de la propaganda o del marketing político. De hecho, el papel de los medios de comunicación $y$ sus enfoques noticiosos también juegan un papel central en la definición de las percepciones y posiciones de la ciudadanía sobre diversos aspectos de la vida política. Esta premisa también vale para el proceso de referendo. Como se señaló al inicio del artículo, de previo al referendo, la gran mayoría de los medios comerciales y sus noticiarios estaban inclinados a favor del TLC, situación que se mantuvo a lo largo del proceso.

\section{LA AGENDA MEDIÁTICA \\ DE LOS PRINCIPALES MEDIOS \\ DE COMUNICACIÓN}

Sin lugar a dudas, un elemento muy efectivo en la configuración de lo que se denomina agenda setting es la construcción de un marco interpretativo de los hechos presentados como noticias por parte de los canales televisivos y periódicos. En el caso del TLC en Costa Rica, existió un claro desbalance mediático debido al evidente tratamiento favorable que le otorgaron estos medios en su enfoque noticioso. De hecho, este tratamiento parcial reforzó la estrategia de campaña mediática de las fuerzas políticas y sectores económicos que apoyaban el Tratado, enfatizando los temas que impulsaba la campaña publicitaria del sí, incluyendo el empleo (generación/pérdida), la estereotipación del NO como movimiento violento y la insinuación, a veces tácita y a veces explícita, de que gobiernos extranjeros apoyaban al No (insinuando el apoyo de Ortega, Chávez y Fidel). La repetición y el envoltorio de "enfoque noticioso" posiblemente le dieron a estos temas un mayor alcance, aunque también contribuyó a que cada vez más ciudadanos pudieran percibir el enfoque parcializado que tienen la mayoría de estos medios comerciales.
En la figura 8 se realiza un balance de las noticias a partir de la información generada por la empresa Controles Video Técnicos de Costa Rica S.A. contratada por el Tribunal Supremo de Elecciones (TSE) para monitorear a los medios de comunicación (para mayor información visitar: $<$ http://www.tse.go.cr/monitoreo/monitoreo. htm>). En este caso, se hicieron las dos siguientes delimitaciones: por un lado, se escogieron los canales 6 y 7 por ser los de mayor cobertura nacional y también canal 13 por ser el canal del Estado. No se analizan los datos de las noticias supuestamente neutrales sobre el TLC que presentaron estos medios, sino solo aquellas que el análisis indica que eran noticias parciales, a favor o en contra. Es decir, interesa evidenciar la parcialidad mediática y noticiosa de estos medios. En esa línea, destacan canal 13 y canal 6 (Repretel) como los canales que tuvieron la mayor parcialidad a favor del TLC con una relación de prácticamente dos noticias favorables por cada noticia que contenía una orientación negativa sobre el TLC. Un papel distinto jugó canal 7 (Telenoticias), el canal comercial que tuvo el mayor porcentaje de noticias con un enfoque negativo del Tratado, aunque siempre menos que las noticias favorables al TLC.

\section{FIGURA 8}

NOTICIAS CON ENFOQUE FAVORABLE AL SÍ Y AL NO (\%) EN LOS CANALES 6, 7 Y 13 PERIODO 22/07/07 AL 06/10/07

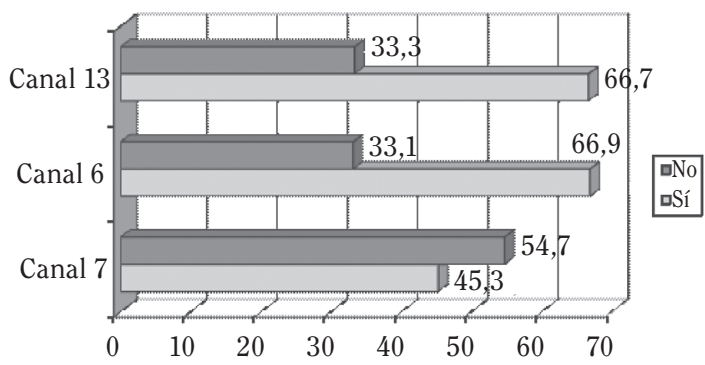

Fuente: TSE. En: <http://www.tse.go.cr/monitoreo/ monitoreo.htm>

En términos de la cantidad de noticias, el canal que le dio mayor cobertura al tema TLC representado en cantidad de noticias fue canal 6: de un total de 891 noticias este canal produjo 525 (63,9\%). Canal 7 produjo $215(29,1 \%)$ y canal 13, 151 (12,7\%) en el mismo lapso. 
Tanto por la cantidad como por el tipo de enfoque, el sesgo noticioso contra el movimiento ciudadano que se oponía al TLC fue muy evidente. Esta situación se agudizó en las últimas dos semanas, como se puede observar en la figura 7, cuando la cobertura mediática y noticiosa a favor del TLC aumentó aún más en el caso de los canales 6 y 13 .

\section{FIGURA 9}

NOTICIAS CON ENFOQUE FAVORABLE AL SÍ Y AL NO (\%) EN LOS CANALES 6, 7 Y 13 PERIODO 23/09/07 AL 06/10/07

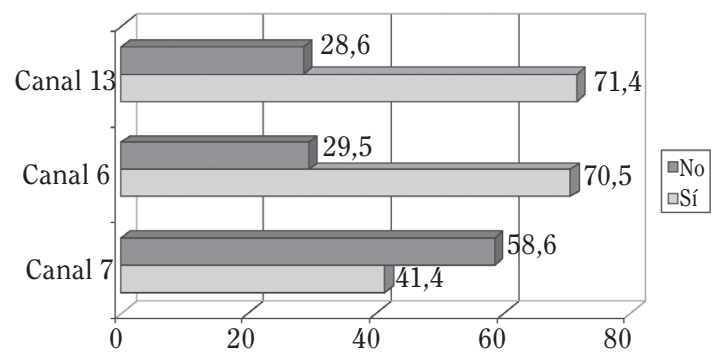

Fuente: TSE. En:<http://www.tse.go.cr/monitoreo/ monitoreo.htm>

Por ejemplo, en el caso del canal estatal (13), en los debates diarios realizados en las mañanas de la última semana solo se entrevistó a partidarios del sí e, incluso, se reprodujo un video musical supuestamente auspiciado por un grupo denominado "Los de Abajo" que llamaba a la violencia y a la insurrección. El grupo mencionado había desmentido varios meses antes que ese video fuera avalado por ellos y más bien denunciaron que había aparecido en su página Web posiblemente como acción de algún hacker favorable al sí.

Volviendo a la figura 8, hay dos aspectos que interesan destacar: primero, el hecho de que el canal estatal terminara siendo el más parcial a favor del Gobierno. Sin lugar a dudas, el TSE debió actuar en este caso concreto para corregir esta situación de desbalance al menos en el caso del canal del Estado y, por tanto, perteneciente a toda la población.

Segundo, que fue evidente que el desbalance se agravó al final del proceso, llegando al extremo de irrespetar la denominada tregua electoral que prohíbe a las partes a hacer proselitismo mediático durante los dos días previos y el propio día de la elección.

Esta violación mediática de la tregua incluyó entrevistas a figuras claves del Sí, empezando por el Presidente y el Ministro de la Presidencia, siguió con la divulgación de una carta de una funcionaria del Departamento de Comercio del gobierno norteamericano en que se indicaba que no había posibilidad de renegociación, sin que se le diera la posibilidad a los sectores opuestos al TLC de responder a estos ataques $y$, finalmente, la repetición de una entrevista del periodista de temas económicos de CNN a un profesor de economía de la Universidad de Georgetown que, en la práctica, lo que hacía era un llamado abierto a votar a favor del TLC so pena, para los costarricenses, de pasar a la catástrofe total de ganar el NO <http:// www.youtube.com/watch? $v=n 2 \_A V P F z X C s>$.

Aunque el impacto de este manejo noticioso requiere de más estudio, la encuesta postreferendo realizada por la Escuela de Ciencias Política de la UCR (Cortés y Fournier, 2008) indica que un $23,6 \%$ de la población entrevistada vio la entrevista CNN durante la tregua y los cruces de diversas variables sugieren que el clima de miedo generado en esos últimos tres días, pudo haber modificado la trayectoria de votación $y$, por tanto, el resultado final del referendo, sobre todo tomando en cuenta que la diferencia final fue cercana al 3\%. Es interesante que esta hipótesis parece ser reforzada por los sondeos de opinión que realizaron Rodríguez, Chacón y Gómez, que indican que el No estuvo arriba del sí hasta tres días antes del referendo (Rodríguez et ál., 2008).

En este caso de violación a la tregua para favorecer al sí participaron la gran mayoría de los programas de noticias nacionales, repitiendo una y otra vez noticias y entrevistas que reforzaban la idea de una catástrofe inminente si no se aprobaba el TLC, campaña que no pudo ser respondida por el Movimiento Patriótico del NO por estar en medio de la tregua. Esta desvirtuación del papel informativo que deberían tener los medios de comunicación para transformarse en meras correas de transmisión de una de las posiciones es parte de lo que diversos académicos y analistas han denominado "fraude mediático" (Garita, 2007). 


\section{LA PARTICIPACIÓN DEL EJECUTIVO}

Aparte de la decisión de no haber garantizado financiamiento público para las dos campañas enfrentadas en el referendo, otra de las decisiones más criticadas del Tribunal Supremo de Elecciones (TSE) fue la de haber permitido que el Presidente de la República pudiera hacer proselitismo, contraviniendo el artículo 95 de la Constitución Política que establece como obligatoria la imparcialidad de las autoridades gubernativas y el artículo 88 del Código Electoral que establece prohibiciones en la misma línea.

El permiso otorgado por el TSE al Presidente le permitió constituirse en la figura principal de la campaña del sí, con todos los recursos simbólicos y materiales que garantiza ser el máximo jerarca del Estado así como con la logística que le garantiza el cargo presidencial. Esta ventaja se manifestó en la utilización de sus giras y de las de sus ministros para realizar proselitismo abierto a favor del TLC. Ello conllevó una trivialización de la figura presidencial que, en función de obtener votos favorables para el TLC, hizo una serie de promesas de corte claramente populistas que reforzaba la política del miedo, la estereotipación de la oposición y la falsa promesa hacia el futuro, con mensajes como los siguientes:

... Los que hoy vienen en bicicleta, con el TLC vendrán en motocicleta BMW, y los que vienen en un Hyundai, vendrán en un Mercedes Benz, en esto consiste el desarrollo (La Prensa Libre, 2007).

En el marco de los festejos oficiales por el 183 aniversario de la Anexión del Partido de Nicoya, realizados en Liberia, señaló que los costarricenses serían reconocidos como unos tontos (sic) ante la opinión pública internacional. En el mismo discurso oficial indicó que serían miles los ticos que se lanzarían del puente de Los Anonos ${ }^{2}$ y donde también reiteró

2 El Presidente hacía referencia al Puente de Los Anonos en Escazú, famoso porque algunas personas se han lanzado desde allí para suicidarse. la advertencia de que, de no aprobarse el tratado, la gente terminaría por irse a otros países, como Nicaragua... (Centro de Comunicación Voces Nuestras; 27/07/07).

Pocas veces en la historia del país se había escuchado un populismo tan rancio, tan falacioso, descalificador $y$ amenazante, como el contenido por los diversos discursos hechos por el presidente Arias en las giras al país. Gracias a las nuevas tecnologías de la comunicación y del papel democratizador de la información que está jugando Internet, se logró capturar uno de estos discursos del presidente Arias en el que, de forma descarada, le ofrecía a una comunidad de la zona sur que venían a “... sellar un pacto: ustedes votan a favor del TLC y nosotros (el gobierno) les construimos un gran aeropuerto..." (Ver en: <http://www.youtube. com/watch? $v=$-hOexwgLT_I $>$ ).

Frente a este evidente uso de los recursos públicos por el Presidente, el papel del TSE fue totalmente nulo y permisivo, dejando de tutelar el derecho ciudadano de tener un presidente imparcial $y$ de poder votar sin coacción y manipulación.

LA CAMPAÑA DEL MIEDO DEL SÍ Y EL MEMORANDO CASAS-SÁNCHEZ

Conforme el proceso de referendo fue avanzando cada vez se hizo más claro que el eje articulador de la campaña del sí (tanto en publicidad como en noticias) era la generación de miedo en la población, sobre todo con la repetición de los siguientes ejes temáticos:

$\diamond$ el uso del tema del empleo (inicialmente exagerando la cantidad de empleos que se iban a crear $y$, posteriormente, enfatizando en el desempleo que se generaría si se rechazaba el TLC);

$\diamond$ el intento de vincular la campaña del No con Chávez, Castro y Ortega;

$\diamond$ la estereotipación del Movimiento Patriótico del No como un movimiento estrictamente sindical o como un movimiento violento.

A ello se agrega, el intento de apropiarse o de neutralizar el símbolo de la campaña 
del No, que era un NO cuya "o" tenía forma de corazón que contenía los colores patrios. A la campaña del No, dada la escasez de recursos y de la parcialidad de la cobertura noticiosa, le era sumamente difícil demostrar las falacias e inexactitudes de la campaña del sí.

Esta situación cambió a partir del descubrimiento de un memorando dirigido al presidente Arias y al Ministro de la Presidencia, cuyos autores eran el vicepresidente de la República en ese momento, Kevin Casas $y$ el diputado liberacionista y pariente del Presidente, Fernando Sánchez. Este documento salió a la luz pública gracias al periodismo de investigación desarrollado por el Semanario Universidad y a la rápida y masiva difusión del documento por Internet, lo que impidió que los medios comerciales de comunicación pudieran silenciar o minimizar el caso.

Más allá de sus implicaciones legales $y$ penales, el memorando básicamente hace un diagnóstico sobre la situación de la campaña del sí y del No en que se evidencia en los autores una gran ansiedad y preocupación por el avance del No, que denominan formidable coalición del NO y la crítica situación de la campaña del sí. Luego del diagnóstico, el memorando incluía una serie de sugerencias sobre lo que había que hacer para lograr el triunfo del sí. En términos de la estrategia de comunicación política, las medidas más importantes eran:

$\diamond$ Evitar la polarización ricos/pobres. Ello implicaba sacar de portavoces del Sí a grandes empresarios, negociadores y ministros del gobierno. Asimismo, llamaban a utilizar a pequeños empresarios, solidaristas, cooperativistas $y$ trabajadores. Hacer muchos testimoniales utilizando a gente sencilla.

$\diamond$ Forzar a los alcaldes a manifestarse a favor del tratado.

$\diamond$ Reforzar varios miedos. Entre ellos, los siguientes:

- Miedo a la pérdida de empleo.

- Miedo al ataque a las instituciones democráticas.

- Miedo a la injerencia extranjera.

- Miedo a una crisis de ingobernabilidad si el gobierno pierde el referendo: gobernarían los sindicalistas e izquierdistas. $\diamond$ Descalificar el discurso del No como mentiroso.

$\diamond$ Sembrar cizaña contra la dirigencia del NO.

A pesar de que el Presidente rechazó haber leído o tomado en serio estas sugerencias $y$ de que la campaña del sí tomó abierta distancia del Memorando, su contenido y sugerencias fueron ejecutadas a cabalidad. Incluso, la campaña del sí fue más allá, en dos líneas: primero, se solicitó la injerencia del gobierno norteamericano para que se pronunciara a favor del TLC reforzando la percepción de que las relaciones bilaterales quedarían en una situación complicada y, segundo, se violó la tregua electoral por figuras claves del sí, incluido el Presidente y el Ministro de la Presidencia y, sobre todo, por los medios de comunicación que hicieron pasar por noticias lo que era proselitismo.

Es posible que la violación de la tregua por los medios, sumado a la campaña del miedo que fue reforzada de manera clara en los últimos días, fueron factores claves para explicar el ajustado triunfo del sí en el referendo.

\section{LA CAMPAÑA DEL NO: LA GENTE} HACE UNA CAMPAÑA DE CAMPAÑAS

Dados lo ajustado del resultado $y$, tomando en cuenta la diferencia de la inversión que hubo entre la campaña del sí y la campaña del $\mathrm{NO}^{3}$, es necesario hacer un breve análisis para entender la efectividad de los opositores al Tratado en términos comunicacionales.

Para iniciar, cabe indicar que no fue una campaña estructurada de la forma en que se hace una campaña presidencial o electoral convencional. No hubo agencias publicitarias (frente a cuatro que trabajaron en el sí). De hecho, el grupo No-Comunicación, que estuvo trabajando en el marco de la coordinación del Movimiento Patriótico del NO al TLC, era una red de periodistas, comunicadores, productores audiovisuales, promotores culturales, artistas y analistas, que

3 Para ponerlo en números, según Media Gurú la relación en gasto publicitario entre el Sí y el NO fue de 9:1. (Semanario Universidad). 
no tenían más vínculo que el deseo de que el No triunfara en el referendo. Sin embargo, aunque la producción audiovisual, escrita y radiofónica de esta red fue muy amplia, de ninguna manera la producción discursiva y simbólica del NO dependió de ella.

La campaña del No fue baja en recursos económicos pero intensiva en gente. Fue una campaña de campañas en la que de forma no centralizada participaron intelectuales, produciendo discurso crítico; los grupos de comunicadores, preparando y produciendo material y generando noticias en los medios; las organizaciones sociales (sindicales, ambientalistas, juveniles, de mujeres, religiosas, etc.), editando $y$ multiplicando el material a distribuir entre sus afiliados y donando material a los Comités Patrióticos; las comunidades, por medio de los Comités Patrióticos que adquirían el material, lo reproducían y distribuían en visitas a hogares, mercados y ferias del agricultor. Fue una dinámica orientada por la mística y el compromiso, lo que generó una movilización y organización inédita en la historia del país. Hoy quedan aproximadamente 200 Comités Patrióticos organizados y luchando por una Costa Rica justa y solidaria.

Sobre el contenido de la comunicación política del Movimiento Patriótico del NO al TLC, hubo diversos ejes que se desarrollaron, algunos estaban orientados a minar los ataques del sí:

$\diamond$ Demostrar que el movimiento era diverso y no solo sindical. En esa línea, entre muchas otras acciones se escogió al Rector del Instituto Tecnológico, Eugenio Trejos, como el vocero principal del movimiento.

$\diamond$ Demostrar el carácter pacífico del Movimiento. De hecho, en prácticamente todas las acciones de movilización que hubo antes $y$ durante el referendo no hubo acciones de violencia desde el No y más bien se logró denunciar la provocación de acciones del sí.

$\diamond$ Demostrar que la campaña de no, no tenía vínculos externos y más bien que era financiada por la gente (campaña: Al No lo Financio Yo).

Otros ejes estaban orientados a movilizar la indignación como emoción característica del NO. $\diamond$ Potenciando la duda en la ciudadanía sobre los grandes intereses económicos ocultos detrás del TLC.

$\diamond$ Asociando a los ricos y sectores económicos voraces con el sí.

También hubo ejes que tenían que ver con el contenido y los posibles efectos del Tratado, incluyendo la amenaza al Estado Social de Derecho y su impacto negativo sobre servicios por las posibles aperturas privatizadoras de las telecomunicaciones, los seguros y el seguro social (propiedad intelectual); la desaparición de los pequeños y medianos agricultores; la amenaza a la soberanía jurídica y territorial; el impacto ambiental negativo.

Para reforzar estas argumentaciones, se utilizó en muchas ocasiones ejemplos de lo ya sucedido en otros países que habían aprobado tratados de libre comercio como México y también ejemplos de los mismos países de la región que ya habían aprobado el Tratado.

Sin embargo, uno de los temas de mayor impacto y más difícil de combatir para el NO fue el miedo que generaba en la ciudadanía la situación que se crearía si no se aprobaba el TLC. El Sí, secundado masivamente por el tinglado de medios noticiosos que lo apoyaban, logró posicionar la creciente sensación y percepción de que el rechazo al TLC implicaría un aislamiento comercial. El debate sobre si seguía o no la Iniciativa de la Cuenca del Caribe (ICC), la posibilidad o no de modificar el Tratado, fueron temas a los que el sí le logró sacar ventaja, sobre todo en la última semana con la intromisión directa del gobierno norteamericano indicando que el asunto era, prácticamente, todo o nada. El hecho de que los medios siguieran repitiendo una $y$ otra vez esta noticia durante la tregua electoral dejó al No con muy poca sino nula capacidad de respuesta en los medios de comunicación comercial que no le dieron el menor espacio a su posición.

Más allá de este punto crítico, cabe destacar que la Campaña del No no tiene parangón en el país. Es la primera campaña de campañas hecha de forma descentralizada y con una participación masiva de la gente en la organización $y$ en la comunicación. No es casual que la alegría, el color, la creatividad y la diversidad estu- 
vieran de su lado y que, con tan pocos recursos, lograran un resultado tan impresionante.

INTERNET COMO NUEVA ARENA DE DISPUTA COMUNICACIONAL

Este artículo no podría concluir sin dejar planteado algunos elementos sobre el papel de Internet en el proceso de referendo. Sin lugar a dudas, fue en este proceso en que, por primera vez, Internet adquiere un papel protagónico a pesar de su todavía baja cobertura. Según la encuesta de la Escuela de Ciencias Políticas, poco menos del $5 \%$ de las personas entrevistadas se informaba por medio de Internet. En el caso de la encuesta de la Escuela de Estadística $y$ el Instituto de Investigaciones Sociales, poco más del $20 \%$ de las personas entrevistadas indicaba que recurrían a Internet para definir su decisión.

Aunque todavía amerita más estudio, se podría decir que este fuerte protagonismo de la red fue potenciado por el hecho de que el NO tuvo que utilizarlo como una forma de superar el bloqueo mediático y la avasalladora campaña publicitaria del sí. Por ejemplo, es muy probable que la rápida y masiva circulación del memorando en Internet y la indignación ciudadana que creó fue clave en que los medios comerciales de comunicación no pudieran silenciar o minimizar este evento, cosa que parecía estaban intentando, a juzgar por el silencio que hubo en los dos primeros días después de que salió la noticia en el Semanario Universidad.

En esa línea, fue un mecanismo esencial para distribuir contra-información, noticias (Noticiero La Otra Cara), material informativo para reproducir en las comunidades de todo el país. De hecho, la gran mayoría de los Comités Patrióticos están enlazados por medio de la lista electrónica "apoyo cantonal". Además, el movimiento desarrolló dos páginas Web oficiales (notlc.com y concostarica.com), aparte de la existencia de muchos sitios Web, blogs y sitios de video en youtube (sitio Kamuk). Incluso, el No logró establecer una estación de radio con transmisiones a Internet (Radio Rebelde).

La lógica de las dos campañas en la red era totalmente distinta: en el caso del sí, la mayor parte de la producción que circulaba en Internet era hecha o por las agencias publicitarias para TV y luego entraban a la red o eran hechas por personas vinculadas a la campaña de forma oficial y el contenido de sus páginas Web era de tono claramente negativo (mandaguevo.com; carepicha.com). En el caso del NO, en la mayoría de los casos, la producción se construía para la red y luego trascendía a los medios convencionales.

Concluyo este apartado indicando dos aspectos importantes: por un lado, el contenido claramente juvenil que tiene el espacio augura que está en camino un cambio significativo en la práctica y cultura política del país y, por otro lado, la creatividad e interactividad que se generó y manifestó en la red fue impresionante y ameritaría una sistematización. Desde mi punto de vista, algunos de los mejores spots y videos de la campaña del no y los mejores golpes comunicacionales contra la campaña del sí se dieron en Internet $y$, en algunos casos, con producciones claramente artesanales, como el famoso caso el video de manguiño que circuló masivamente por la red $y$ allende.

\section{CONCLUSIONES}

En términos de la comunicación política en una sociedad democrática se derivan varias conclusiones:

Primero, que uno de los puntos más débiles del proceso de referendo fue la falta de financiamiento público para la campaña, situación que favoreció claramente al sí por el apoyo abierto que tenía del gran capital. Es una situación que debe corregirse en un futuro inmediato garantizando financiamiento público para las partes y la prohibición de financiamiento privado, fuente permanente de corrupción.

Segundo, el referendo es un proceso de consulta ciudadana y la participación sin restricción del ejecutivo generó y seguirá generando desequilibrios que no se podrán evitar, incluyendo la tentación de utilizar recursos públicos para hacer proselitismo. Para fortalecer la democracia ciudadana $y$ participativa que merece Costa Rica en el siglo Xx, hay que prohibir que el Presidente haga proselitismo en 
referendos, tal y como sucede en los procesos electorales.

Tercero, los medios de comunicación quedaron en deuda con la ciudadanía y con la democracia por su parcialidad abierta, por la baja calidad de la cobertura periodística y por la poca importancia que le otorgaron al debate público. Es en este punto donde se ubica uno de los mayores desafíos para nuestra buena convivencia política. Necesitamos mayor calidad en los medios actuales y más medios de comunicación que reflejen, de forma honesta $y$ profesional, la variopinta diversidad política $y$ ciudadana que tiene la Costa Rica del siglo XXI.

Cuarto, el papel jugado por Internet genera esperanzas sobre la posibilidad de democratizar la comunicación política en el futuro. La inevitable expansión de la red, su carácter interactivo y la presencia masiva de nuestra juventud es una señal positiva para la construcción de una comunicación política más reflexiva $y$ democrática.

Quinto, es necesario hacer un proceso de evaluación y de rendición de cuentas del árbitro, el TSE. Su permisividad con el sí ralló en la complicidad y fue mucho más allá de lo que le permite la Constitución Política y el Código Electoral. Es necesario un aggiornamiento del TSE para acabar con los abusos y las prácticas estipuladas del Memorando Casas-Sánchez, que solo denigran la práctica democrática.

Sexto, es interesante destacar como no siempre más recursos garantizan una mejor comunicación política. En este proceso, el sí con sus recursos inagotables terminó haciendo una campaña publicitaria convencional con prácticas políticas propias de la Costa Rica de inicios del siglo Xx frente a una campaña del NO escasa en recursos pero llena de colores, creatividad y mística, construida desde abajo por la gente. Desde mi punto de vista, allí radica el germen de la comunicación política democrática que requiere nuestro país en el siglo XXI. Solo con un pueblo más consciente, más reflexivo, podremos derrotar las campañas del miedo, la mentira y el dinero. Para ello debemos hacer de la política un espacio de encuentro y de educación ciudadana. Esa es la enseñanza que nos dejó la Campaña del No y sus Comités
Patrióticos y ese es el desafío que tenemos para construir una verdadera democracia ciudadana $y$ participativa en el siglo XXI.

\section{BIBLIOGRAFÍA}

Cortés Ramos, Alberto. "El retorno del expresidente Arias (2006): ¿fin de la transición costarricense?". L'Ordinaire Latino-américain 206, enero-abril. 2007: 39-63.

Cortés Ramos, Alberto y Marcos Fournier Facio. Encuesta sobre el TLC y el referendo. Escuela de Ciencias Políticas, Universidad de Costa Rica. 2007.

Encuesta Post-referendo. Escuela de Ciencias Políticas, Universidad de Costa Rica. Abril, 2008.

Del Rey Morató, Javier. Comunicación política, internet y campañas electorales. De la teledemocracia a la ciberdemocracia. Madrid: Editorial Tecnos, 2007.

Monzón, Cándido. Opinión pública, comunicación y política. Reimpresión. Madrid: Editorial Tecnos, 2000.

Pérez García, David. Técnicas de comunicación política. El lenguaje de los partidos políticos. Madrid: Editorial Tecnos, 2003.

Poltronieri, Jorge. Encuesta estructura de opinión pública. Escuela de Matemáticas, Universidad de Costa Rica. 2006.

Rodríguez, Florisabel; Gómez Barrantes, Miguel y Wendy Chacón. "El Referéndum del TLC del 2007 en Costa Rica: evaluación de un instrumento ciudadano" (borrador). Ponencia para el Congreso ¿Gobernanza sin desarrollo? Repensar el bienestar en América Latina. San José. Agosto, 2008. 
Rospir, Juan Ignacio. "Introducción a la comunicación política”. Berrocal, Salomé (coordinadora). Comunicación politica en televisión y nuevos medios. Barcelona. Editorial Ariel, 2003: 21-54.

PUBLICACIONES PERIÓDICAS

Garita, Nora. "Fraude mediático en Costa Rica”. Le Monde Diplomatique. París. Diciembre, 2007.

La Prensa Libre. Discurso del Presidente Óscar Arias ante trabajadores de la empresa Techno Park en Cartago, 30/05/2008.
Semanario Universidad. Presidente Arias comprometido con grupos empresariales. Semana del 04 al 10 de octubre, 2007.

Voces Nuestras. Discurso Oficial del presidente Óscar Arias con motivo de la Anexión de Guanacaste. Centro de Comunicación Voces Nuestras, 27/07/2007.

BASES DE DATOS

Tribunal Supremo de Elecciones. En: <http:/ www.tse.go.cr/monitoreo/monitoreo. htm> 
